\title{
Smart University: The Integration of Artificial Intelligence in Higher Education to Resolve the Training/Employment Inadequacy
}

\author{
Ait Bennacer Fatima-Ezzahra ${ }^{1}$, Aaroud Abdessadek ${ }^{2}$, Akodadi Khalid ${ }^{3}$, Cherradi \\ Bouchaib $^{4}$ \\ ${ }^{1,2,3,4}$ Laroseri Lab., Department of Computer Science, Faculty of Sciences, Chouaib Doukkali University, El Jadida, \\ Morocco
}

\begin{abstract}
In Morocco and according to HCP data, the unemployment rate increases proportionally to education level. This paradox confirms the inadequacy of training with the job market needs and the permanence development that does not achieve much progress in a world increasingly laborious and demanding [1]. In front of company transformations that obviously influence the job market, there is a growing gap between training offered in higher education and the real needs expressed by companies [2]. A situation that aims to limit employment opportunities for young people, and thus increase the unemployment rate among this section of the population.

In order to ensure a transparent integration of its graduates in the job market, industries and organizations, universities confront many challenges. Which requires a multidisciplinary approach: education combined with complementary skills [3]. Artificial intelligence represents a huge opportunity for improving education quality, especially through personalized training paths based on needs, filling gaps or overcoming difficulties. The fast rhythm of technological innovation and the ensuing job movements prove that higher education requires a reexamination of the roles and pedagogy of teachers [4]. According to [5], this revolution must link education to employment. Employers need to collaborate with schools and universities to develop curricula and share their practical knowledge of the marketplace. By this work, we try to propose a new approach to ensure both the adequacy of university training and the integration of students into labor market. The aim is to resolve the problem by updating the existing curricula according to the most demanded skills on the local, national and international markets. Consequently, reducing the gap between the offer of higher education and the labor market, through the integration of artificial intelligence techniques and methods, in order to focus on the improvement and adequacy of the training offered, which is still too rare in the continent with regard to its potentialities.
\end{abstract}

Keywords: Training Engineering, Orientation, Soft Skills, Deep Learning, Data Mining. 